\title{
Design of Used PET Bottles Crushing Machine for Small Scale Industrial Applications
}

\author{
Ikpe Aniekan E.*\$, Owunna Ikechukwu** \\ $* \$$ Department of Mechanical Engineering, University of Benin, Nigeria \\ **Department of Mechanical Engineering, University of Benin, Nigeria \\ (ikpeaniekan@gmail.com, ikechukwu.owunna@uniben.edu)
}

*Corresponding Author: Ikpe Aniekan, Room 142, Mechanical Engineering Department, University of Benin, Nigeria,

Tel: +2349024773812, E-mail: ikpeaniekan@gmail.com

Received: 07.07.2017 Accepted: 22.09.2017

\begin{abstract}
In this study, PET bottles crushing machine was designed to convert used PET bottles into shreds readily available for recycling. Preliminary tests and mechanical factors were extensively evaluated on the conceptual designs to ensure that the concept with optimal performance and efficiency is selected. Experimental test was conducted to determine the power required to overcome the shear stress of the PET bottles and it was found out that $10 \mathrm{hp}$ was the power required. With a set of crushing forces ranging from 1000-3000N, Finite Element Analysis (FEA) was performed for five different scenarios on the 201 Annealed Stainless Steel cutting blade to inspect the material response to stresses and corresponding deformations. The maximum von Mises stress was $2.089 \mathrm{e}+006 \mathrm{~N} / \mathrm{m}^{\wedge} 2$. The material yield strength was found to be $2.92 \mathrm{e}+008 \mathrm{~N} / \mathrm{m}^{\wedge} 2$, and applying a force of $3000 \mathrm{~N}$ on the cutting blade produced a maximum displacement of $2.220 \mathrm{e}-003 \mathrm{~mm}$. This therefore imply that the material will not deform or fail under a force equal to or below the material yield strength value. Tests carried out on the final machine design indicated efficiency of $82.2 \%$ which is only $6 \%$ less than the efficiency of existing ones.
\end{abstract}

Keywords: PET bottles, Crushing, Design, Machine, non-biodegradable, Environment.

\section{Introduction}

One of the prevalent environmental problem encountered in most developing countries is Solid Waste Management (SWM). Waste has been defined as any material that is of no value to the owner, and therefore disposed as waste [1]. Municipal solid waste (MSW) also known as urban solid waste is defined as non-air and sewage emissions generated within and disposed by the municipality. These includes household waste, commercial refuse, construction and demolition debris, dead animals and abandoned vehicles [2]. MSW is mainly characterized by paper, vegetable matter, plastics, textiles, metals, rubber and glasses [3]. MSW management is gradually becoming a plague that requires immediate attention for optimum protection of public health and environment. This is as a result of increasing population growth, high rate of consumption, urbanization, lack of effective waste management plan etc. [4]. In recent times, studies have shown that apart from the environmental pollution and contamination of ground water by organic waste, plastic waste such as polyethylene terephthalate (PET) bottles is one of the waste management problems hampering the developmental and aesthetical state of our environment as a result of its indiscriminate disposal.

Polyethylene terephthalate is a polyester made from terephthalic acid (a di-carboxylic acid) and ethylene glycol (a di-alcohol) through the process of polymerisation. Since the introduction of PET bottles over 60 years ago, it has been a means of packaging water, juices, carbonated soft drinks, edible oil, liquor, chemicals etc. However manufacturers as well as consumers have grown increasing interest in the use of PET bottles due to a number of reasons [5].

In attempt to prevent sharing of drinking cups and maintain hygiene, PET bottles became widely acceptable because they are disposable, cheap, lightweight and made of durable materials which can readily be moulded into different 
shapes and sizes relevant to a wide range of applications [6]. As a result of the world's increasing population which is about 7 billion people, there has been a high tendency for empty PET bottles to increase. The global PET packaging market was worth $\$ 48.1$ billion in 2014, amounting to almost 16 million tons according to a new market report. Demand for PET packaging is expected to increase by an average of $4.6 \%$ annually over the next five years, and will amount to 19.9 million tons, worth $\$ 60$ billion by 2019 . With overall PET packaging consumption of 15.4 million tons in 2013, PET bottles for beverages accounted for over $80 \%$ of overall sales at 12.5 million tons (up to $3.7 \%$ on 2012). In 2013, bottle water became the largest category for PET packaging; sales of PET water bottles grew by $7.3 \%$ reaching 5.45 million tons [7]. This statistic poses a great environmental risk as a result of the fact that bottles made of polyethylene terephthalate (PET) material is non-biodegradable and can spend millions of years in the ground with little or no decomposition [8]. The huge quantities of PET bottles currently being marketed and consumed possibly find their way into waste dumpsites [9], and this creates serious environmental problems.

However, indiscriminate disposal of PET bottles and other non-biodegradable materials end up clogging drainage systems during raining season, causing flood and waterlog in residential areas which consequently serve as breeding ground for vectors such as mosquitoes. The inert nature of PET bottles renders them resistant to bio-degradation which leads to an increase in the amount of PET bottle wastes in dump sites [14, 15]. Moreover, the presence of plastic wastes in the environment is considered hazardous due to their potentials to catch fire easily. It also has negative effect on arable soil especially for farming purpose. Consequently, action should be taken to promote recycling of plastic bottles. According to Oseni [10], plastics which typically exemplifies PET bottles are more or less non-biodegradable as they remain undecomposed in the ground for several thousands of years.

Recycling is an aspect of environmental engineering that deals with the development of technically reasonable solutions to environmental problems which may involve designing a sustainable approach that can convert waste materials to useful items, thereby, avoiding the use of virgin raw materials which depending on the production process may constitute high level of environmental pollution, require high energy input and huge cost of production [11]. According to Tukur [5], manufacturing of PET bottles from virgin raw materials require high energy input with increasing $\mathrm{CO}_{2}$ emission, and since plastics are not degradable materials, its accumulation after use contributes significantly to the prevalent problems bedeviling sustainable environmental protection practices. Recycling of PET bottles is bound to realize a lot of saving in production costs, conserve limited resources, and alleviate environmental pollution [12].

PET bottles crushing machine is that which performs the function of crushing PET bottles or plastic materials into granules or shreds for recycling and production of new products rather than using virgin raw materials for production [13]. This study is focused on the design of a crushing machine for handling of used PET bottles. From the aforementioned points of view, crushing of PET bottles for recycling is cheaper than manufacturing the bottles from virgin raw material, and can also help in controlling the waste disposal problems ravaging the environment particularly in developing countries. For this reasons, there is a need for expansion of plastic recycling programs as well as cheaper machines to handle the problems associated with plastic waste management particularly PET bottles which has a wide range of application worldwide.

\section{Methodology}

To design the PET bottle crushing machine, two design concepts were considered as shown in Fig 1 and 2. The functional requirements considered included cost, safety, functionality, performance and reliability as presented in the decision matrix shown in Table 1. Experimental test was carried out in the workshop using a guillotine equipment to determine a set of forces required to crush empty PET bottles into shreds. Using SOLIDWORKS 2017 version, detailed computer aided design of the selected design concept was represented and stress analysis was carried out on the crushing blade to determine its integrity in actual service conditions.

\subsection{Design Concept one (Simple Crank Mechanism)}

Crank Mechanism as the name implies uses a simple crank mechanism to perform its crushing operation. The mechanism generally consists of a crank wheel connected to a reciprocating arm which usually terminates in a sliding piston. The crank is connected to the power source, while the reciprocating arm converts the rotary motion of the crank to reciprocating motion which is transferred to the piston where work is done. This is the prevailing mechanism in motor vehicles and reciprocating compressors. The major parts of the machine were fabricated using mild steel, this is because it is easy to join among all other metals. Above all, it is a very versatile metal, necessitating its use by many industrial applications. Apart from its versatility, it is also very cheap and readily available for use. Fig. 1 shows isometric skeletal view of design concept one (Simple Crank Mechanism. 


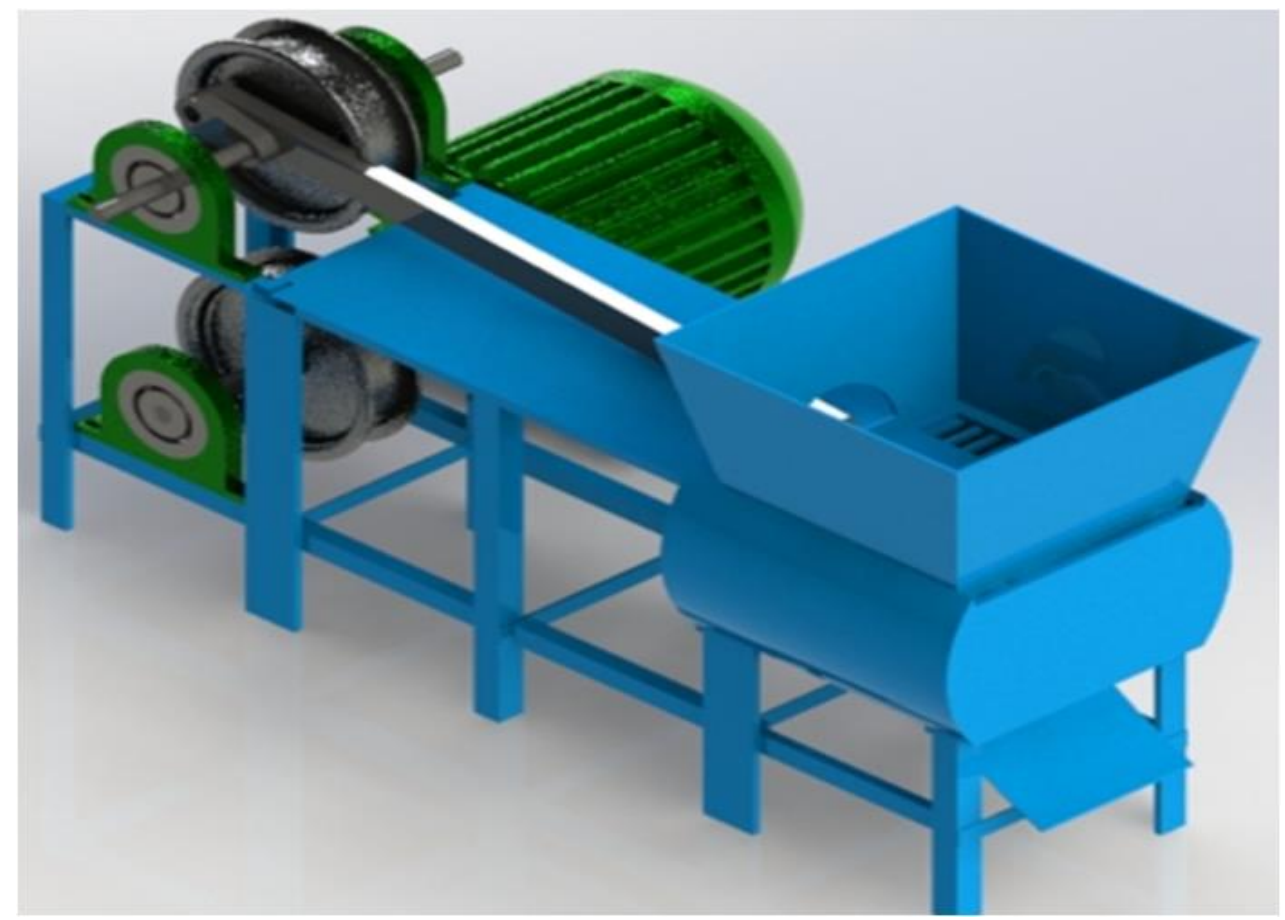

Fig. 1. Isometric view of a Simple Crank Mechanism.

The machine comprises of a motor at the base and a table with the hopper on the opposite end. Compressed or flattened bottles are loaded through the hopper. Power is generated by a motor at the base of the machine and thus, transmitted to the blade shaft through a belt to the pulley located at the blade shaft. The crank is attached to the pulley through the crank pin. A reciprocating arm is connected from the crank pin through the side into the base of the hopper. The end of the arm ends in a blade which slides in the hopper thus carrying out the shredding action. The crushing compartment is separated from the collection unit by a mesh which helps to control the size of pellets at the output of the machine. The large size particles remain in the crushing compartment for crushing.

\subsection{Design concept two (Rotary blade against a fixed blade)}

Design concept two applies the action of a rotational blade against a fixed blade in the hopper to crush PET bottles contrary to the reciprocating action of the slider crank. The machine consists of a hopper and a frame made from angle bars. The hopper which has a voluminous inlet through which the PET bottles are fed into the machine, is mounted directly over the blades and the crushing compartment. They are secured to the frame by bolts and nuts. The rotary blade which is fixed to a shaft is designed with 201 Annealed Stainless Steel (SS) due to its good corrosion and wear resistance properties. The collector unit consist of a perforated curved plate to serve as a mesh for size control. During crushing action, the PET bottles are loaded into the machine through the hopper. The shaft rotates the loaded PET bottles into the space between the fixed blades, this allows the blade to exert enough force to overcome the shear resistance of the bottles. The fixed blade is bolted to the frame and cuts across the crushing compartment. The main important components of the machine are the frame, hopper, fixed and rotary cutters, pulleys, electric motor, bearing, perforated barrel as shown in Fig. 2. 


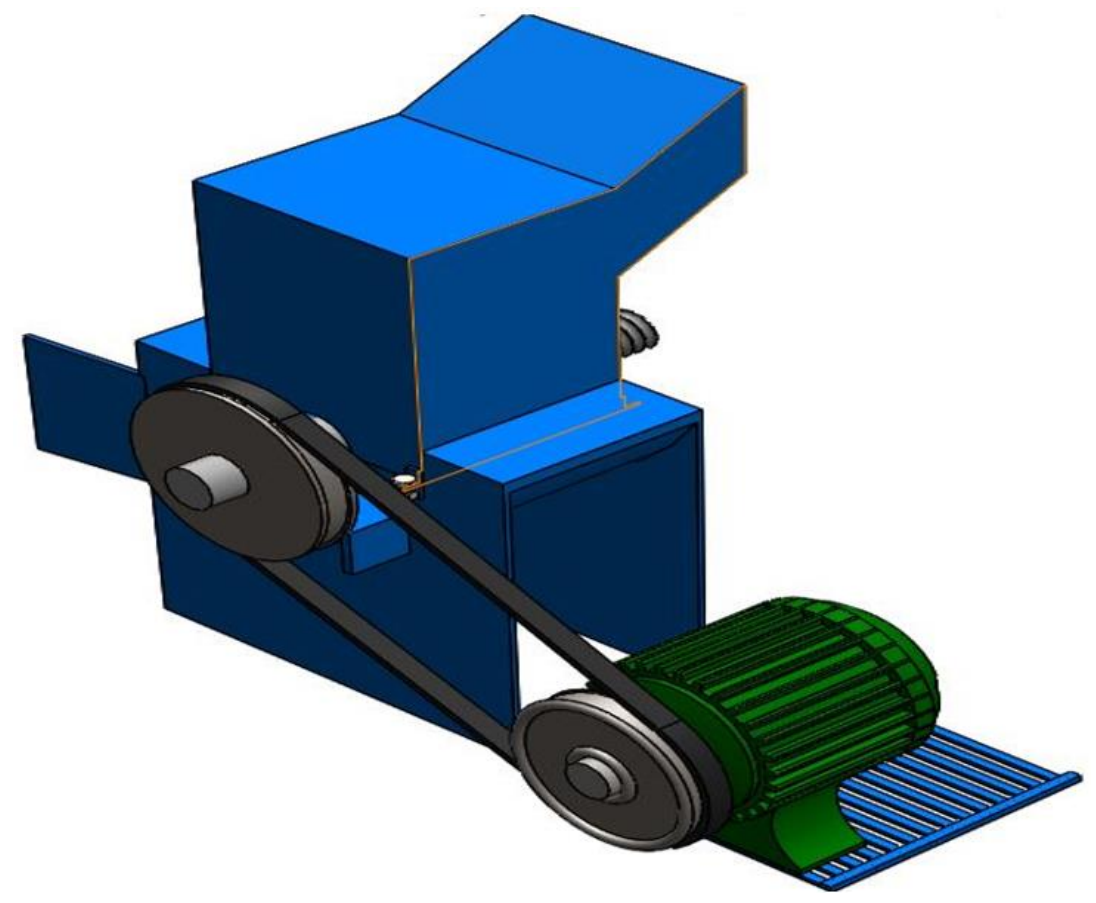

Fig. 2. Isometric view of design concept two Second (Rotary blade against a fixed blade).

The frame also guides, supports and holds in accurate alignment all the moving members of the operating machine. The barrel that houses the cutting chamber is perforated with a hole of $5 \mathrm{~mm}$ so that the crushed PET bottles can pass through it into a collecting trough. The machine is also powered by electric motor via belt drive connected to the main shaft that turns the rotary cutters. Bulk of the parts in the machine were fabricated using mild steel due to its high strength, toughness, and weldability as a result of low carbon content, but however not readily tempered. PET bottles are fed into the hopper inlet without material preparation. The empty PET bottles settle down in the barrel that has in it fixed and rotary cutters made of high carbon steel. The rotary cutters are set into motion by switching on the 10 horse power electric motor that runs at $1440 \mathrm{rpm}$. Also, there is a clearance between the fixed and rotary cutters where the PET bottles drop as they are loaded from the hopper inlet and are constantly being smashed by the rotary cutters repeatedly until they are crushed. The crushed particles in the perforated barrel drops under gravity through the perforations of about $5 \mathrm{~mm}$ and collected underneath with a trough.

\subsection{Selection of Suitable Design Concept}

Decision matrix was used to select the best concept for detailed design and fabrication. A decision matrix is a list of values in rows and columns that allow engineers to analyze and rate the performance relationship between a set of values and information. Each category is assigned a weighing factor based on the design characteristics which measure its relative importance (Norton, 1999). The design decision matrix proposed for the two concepts in this study is presented in Table 1.

Table 1. Decision matrix

\begin{tabular}{|c|c|c|c|c|c|c|}
\hline Functional Requirement & Functionality & Performance & Reliability & Safety & Cost & RANK \\
\hline Ratings & 0.30 & 0.25 & 0.20 & 0.15 & 0.10 & 1.0 \\
\hline First Design Concept & 6 & 2 & 4 & 2 & 4 & 3.8 \\
\hline Second Design Concept & 1.5 & 2.25 & .0 & 9 & & 7.6 \\
\hline
\end{tabular}

Based on the ranking, the second design concept was selected for detailed design and fabrication. However, the first design concept was not considered due to material loss as a result of friction between rubbing surfaces such as the sliding parts and the frame as well as the space occupied by the machine. However, Design concept 2 was selected for its cost, portability, safety, functionality, reliability and above all, its ranking in the design decision matrix shown in Table 1.

\section{Experimental Design Theories}

The shearing forces required to cut the PET bottles were determined using a guillotine equipment represented in Fig. 3. 


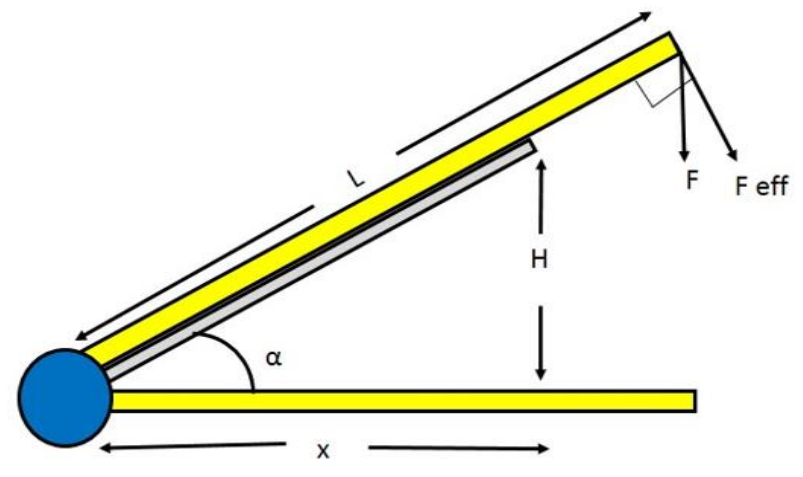

Fig. 3. Analysis of a guillotine equipment.

Where,

$F$ eff is the effective cutting force required (applied normal to the Handle)

$L$ is the length of the force from the pivot

$x$ is the horizontal length of the gutting blade from the pivot

$H$ is the height of the blade from the Base

$F$ is the cutting force applied to the Handle

$\alpha$ is the angle Between the blade and the base

$L b$ is the length of the cutting blade

Now if a force $\mathrm{F}$ is applied at the handle, the equation for the effective force is given by:

$F$ eff $=F \cos \alpha$

Fig. 4 represents the schematic diagram of forces acting at the handle of the guillotine equipment.

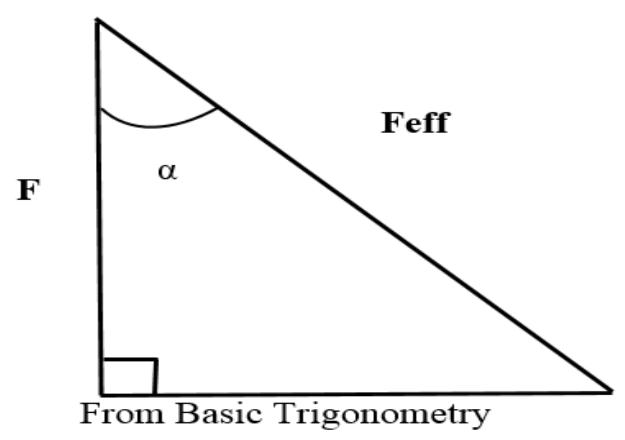

Fig. 4. Schematic of Forces acting at the Handle.
$\operatorname{Cos} \alpha=\frac{\mathrm{x}}{\mathrm{Lb}}$

$\mathrm{F}$ eff $=\frac{\mathrm{mgx}}{\mathrm{Lb}}$

We know that torque is the turning force of the blades

Stress $=\frac{\mathrm{F}_{\text {eff }}}{\text { Area }}$

Where,

Area $=$

Thickness of blade * Length in contact with bottle

Therefore the equation for Power is given by

Power $(\mathrm{p})=$

Torque (T) x Angular speed of motor $(\omega)$

$\mathrm{P}=\mathrm{T} \times \frac{2 \pi \mathrm{N}}{60}$

Where $\omega=\frac{2 \pi N}{60}$

$T=F \times r$

Where $r=$ radius of the blade. The expression shown in equations 10,11 and 12 were considered for the determination of the shaft speed.

$\frac{D_{1}}{D_{2}}=\frac{N_{2}}{N_{1}}$

$\mathrm{N}_{2}=\frac{\mathrm{D}_{1} \mathrm{~N}_{1}}{\mathrm{D}_{2}}$

$\mathrm{N}_{1}=\frac{\mathrm{D}_{2} \mathrm{~N}_{2}}{\mathrm{D}_{1}}$

Where,

$\mathrm{D}_{1}=$ Pitch diameter of the driven pulley

$\mathrm{D}_{2}=$ Pitch diameter of the driver pulley

$\mathrm{N}_{1}=$ Rotational Speed of the driven pulley

$\mathrm{N}_{2}=$ Rotational Speed of the driver pulley

Schematic showing all the forces and reactions on the shaft is presented in Fig. 5. 


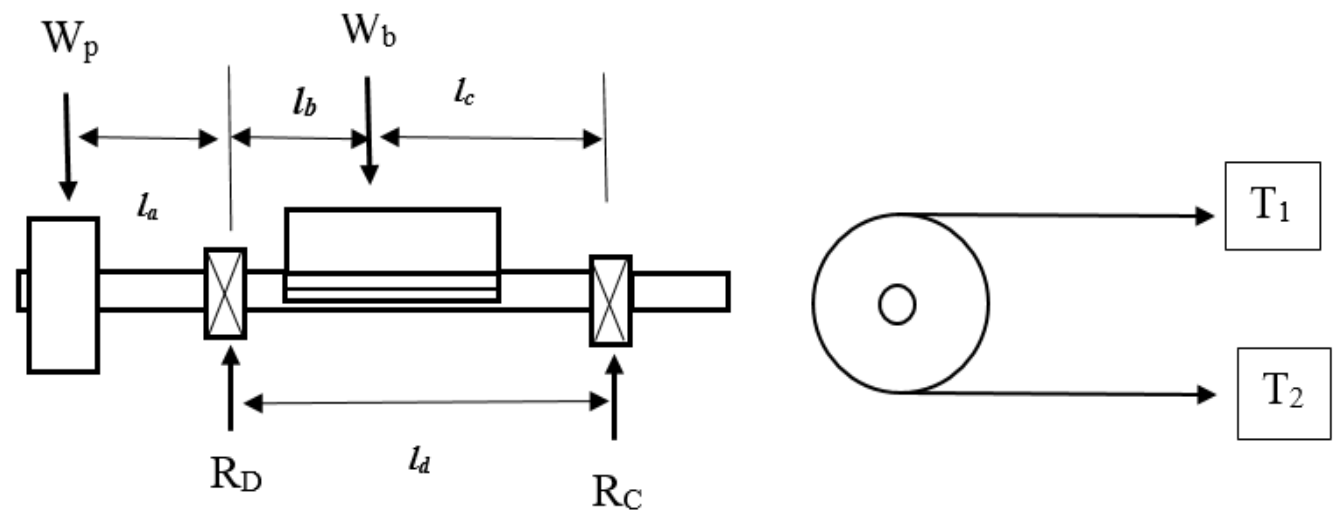

Fig. 5. Schematic Diagram of Weight and Bearing Reactions.

Where,

$\mathrm{W}_{\mathrm{p}}=$ Measured weight of pulley

$\mathrm{W}_{\mathrm{b}}=$ Measured weight of the blade

$\mathrm{R}_{\mathrm{C}}=$ the reaction of bearing $\mathrm{A}$

$\mathrm{R}_{\mathrm{D}}=$ the reaction at $\mathrm{B}$

$\mathrm{T}_{1}=$ the tension in belt on the tight side

$\mathrm{T}_{2}=$ the tension in the slack side

$\mathrm{W}_{\mathrm{R}}=$ the sum of all the upward forces

Therefore,

$W_{R}=W_{b}+W_{p}$

$\mathrm{W}_{\mathrm{b}}=225 \mathrm{~N}$

$\mathrm{W}_{\mathrm{p}}=3672.17 \mathrm{~N}$

\section{Results and Analysis}

This section presents the results obtained from the different task mentioned in the Methodology (section 2 above).

\subsection{Experimental Results for Shearing Force and power}

An experiment to determine the shear force required to overcome the shear resistance of PET bottles was carried out using PET bottle samples with different strength requirements. A guillotine cutter was used to cut the flattened bottle under the influence of some desired dead weights. The experimental results are presented in Table 2. The results obtained for masses, crushing time and Machine Through put Capacity (MTC) of the PET bottles crushing Machine is tabulated in Table 3. Fig. 6 shows a graph of torque against effective force and crushing force, while Fig. 7 shows a graph of crushing power against crushing force.

Table 2. Results Obtained from Experimental Test

\begin{tabular}{|c|c|c|c|c|c|c|c|}
\hline $\begin{array}{c}\text { Mass } \\
(\mathrm{Kg})\end{array}$ & $\begin{array}{c}\text { Weight } \\
(\mathrm{N})\end{array}$ & $\begin{array}{c}\text { Effective } \\
\text { Force } \mathrm{F}_{\text {eff }} \\
(\mathrm{N})\end{array}$ & $\begin{array}{c}\text { Shear } \\
\text { Stress }\left(\mathrm{N} / \mathrm{m}^{2}\right)\end{array}$ & $\begin{array}{c}\text { Crushing } \\
\text { Force } \mathrm{F}_{\mathrm{c}} \\
(\mathrm{N})\end{array}$ & $\begin{array}{c}\text { Torque } \\
(\mathrm{N} / \mathrm{m})\end{array}$ & $\begin{array}{c}\text { Power } \\
(\mathrm{KW})\end{array}$ & $\begin{array}{c}\text { Power } \\
(\mathrm{Hp})\end{array}$ \\
\hline 30 & 294.3 & 292.9623 & 2929623 & 219.7217 & 30.76103864 & 1.546234 & 2.0735 \\
\hline 35 & 343.35 & 341.7893 & 3417893 & 256.342 & 35.88787841 & 1.80394 & 2.419084 \\
\hline 40 & 441.45 & 390.6164 & 3906164 & 292.9623 & 41.01471818 & 2.061646 & 2.764667 \\
\hline 45 & 490.5 & 439.4434 & 4394434 & 329.5826 & 46.14155795 & 2.319352 & 3.11025 \\
\hline 50 & 539.55 & 488.2705 & 4882705 & 366.2028 & 51.26839773 & 2.577057 & 3.455834 \\
\hline 55 & 588.6 & 537.0975 & 5370975 & 402.8231 & 56.3952375 & 2.834763 & 3.801417 \\
\hline 60 & 637.65 & 585.9245 & 5859245 & 439.4434 & 61.52207727 & 3.092469 & 4.147001 \\
\hline 65 & 686.7 & 634.7516 & 6347516 & 476.0637 & 66.64891705 & 3.350174 & 4.492584 \\
\hline 70 & 735.75 & 683.5786 & 6835786 & 512.684 & 71.77575682 & 3.60788 & 4.838167 \\
\hline 75 & 784.8 & 732.4057 & 7324057 & 549.3043 & 76.90259659 & 3.865586 & 5.183751 \\
\hline 80 & 441.45 & 781.2327 & 7812327 & 585.9245 & 82.02943636 & 4.123292 & 5.529334 \\
\hline
\end{tabular}




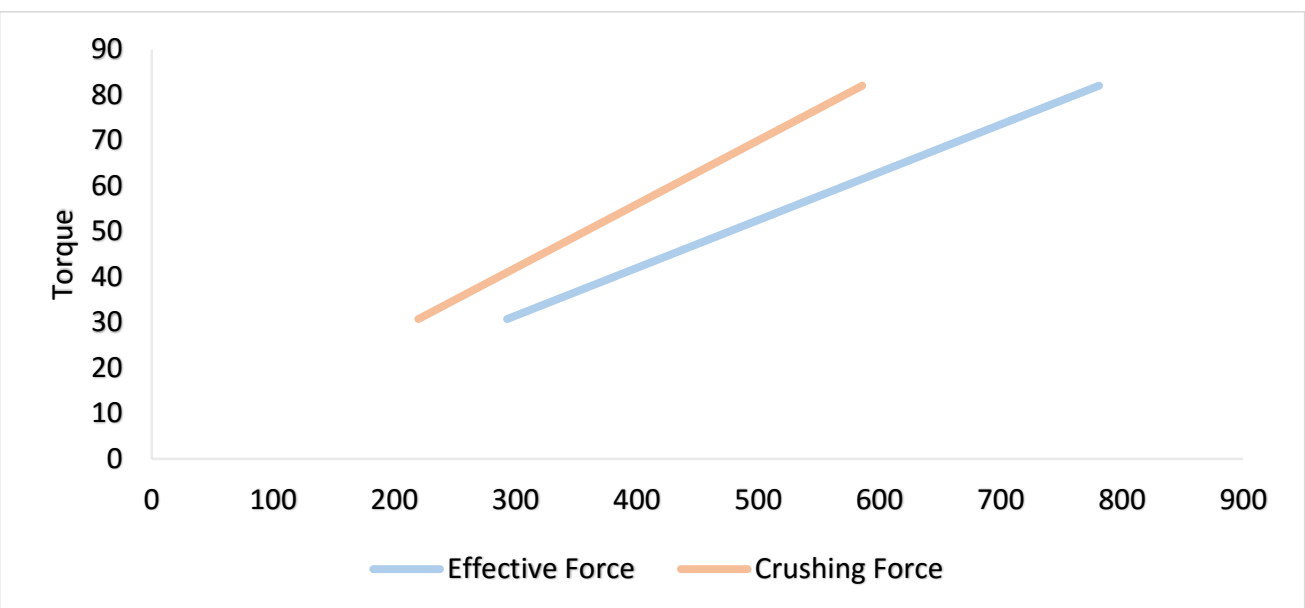

Fig. 6. Graph of Torque against Effective Force and Crushing force.

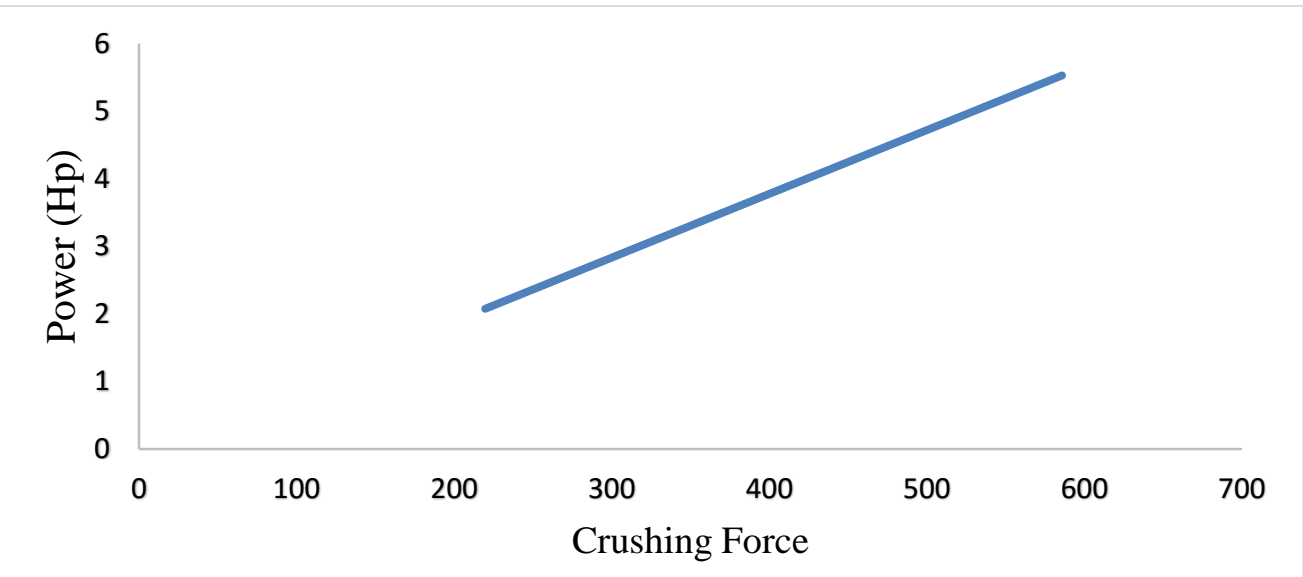

Fig. 7. Graph of Crushing Power against Crushing Force.

Table 3. Result for Masses, Crushing time and MTC of the Crushing Machine

\begin{tabular}{|c|c|c|c|c|}
\hline $\mathrm{S} / \mathrm{N}$ & $\begin{array}{c}\text { Mass of PET Bottles fed } \\
\text { into crushing machine } \mathrm{M}_{1} \\
(\mathrm{~kg})\end{array}$ & $\begin{array}{c}\text { Mass of properly } \\
\text { crushed PET Bottles } \\
\mathrm{M}_{2}(\mathrm{~kg})\end{array}$ & $\begin{array}{c}\text { Crushing } \\
\text { Time }(\mathrm{s})\end{array}$ & $\begin{array}{c}\text { MTC } \\
(\mathrm{kg} / \mathrm{s})\end{array}$ \\
\hline 1 & 3.4 & 1.8 & 56 & 0.061 \\
\hline 2 & 9.6 & 6.2 & 104 & 0.092 \\
\hline 3 & 16.7 & 11.6 & 122 & 0.137 \\
\hline 4 & 20.4 & 15.4 & 144 & 0.142 \\
\hline 5 & 24.8 & 20.1 & 248 & 0.136 \\
\hline 6 & 30.2 & 25.7 & 294 & 0.122 \\
\hline 7 & 36.3 & 32.3 & 338 & 0.123 \\
\hline 8 & 43.4 & 38.5 & 420 & 0.154 \\
\hline 9 & 64.7 & 47.9 & 537 & 0.124 \\
\hline 10 & 66.5 & 52.4 & 649 & 0.109 \\
\hline 11 & 70.6 & 57.2 & 702 & 0.109 \\
\hline 12 & 76.7 & 66.4 & 824 & 0.097 \\
\hline 13 & 80.2 & 69.8 & 832 & 0.101 \\
\hline 14 & 83.9 & 70.6 & 898 & 0.096 \\
\hline 15 & 86.0 & 72.5 & 984 & 0.094 \\
\hline 16 & 92.2 & 75.7 & 1010 & 0.096 \\
\hline 17 & 96.7 & 79.4 & 1016 & 0.103 \\
\hline 18 & 104.6 & 84.8 & 5,360 & 2.024 \\
\hline$\Sigma$ & 1006.9 & 828.3 & 520 & 0.112 \\
\hline Ave & 56.0 & 46.02 & & \\
\hline
\end{tabular}


The machine through put capacity is calculated from equation (14)

$M T C=\frac{M_{1}}{T}$

Where,

MTC = Machine through put capacity

$\mathrm{M}_{1}=$ Mass of used PET bottle fed into the machine

$\mathrm{M}_{2}=$ Mass of crush PET bottle plastic waste

$\mathrm{T}=$ Machine crushing time

The mass of PET Bottles fed into crushing machine $\mathrm{M}_{1}$ (kg) was used for testing the crushing efficiency of the machine for each interval, and this was carried out for eighteen times during which the input $\left(\mathrm{M}_{1}\right)$ and the output $\left(\mathrm{M}_{2}\right)$ were recorded accordingly. Applying equation (15), the average of used PET bottles fed into crushing machine and the output were determined, and these values were substituted into equation (16) to calculate the efficiency of the plastic crushing machine.

$$
\begin{aligned}
& \text { Ave. }=\frac{\sum}{S / N} \\
& \mathrm{C}_{\text {eff }}=\frac{\text { Output }}{\text { Input }} * 100=\frac{\text { AveM }_{2}}{\text { AveM }_{1}} * 100
\end{aligned}
$$

The output is the mass of empty PET bottles properly crushed while the input is the mass of empty PET bottles fed into the crushing the machine. These masses were substituted into equation (16) to determine the crushing efficiency of the machine as follows.

$$
\mathrm{C}_{\text {eff }}=\frac{46.02}{56.0} * 100=82.2 \%
$$

The results obtained indicated that the machine is $82.2 \%$ efficient. A graph of mass of properly crushed PET plastic waste bottle against crushing time is shown in Fig. 8.

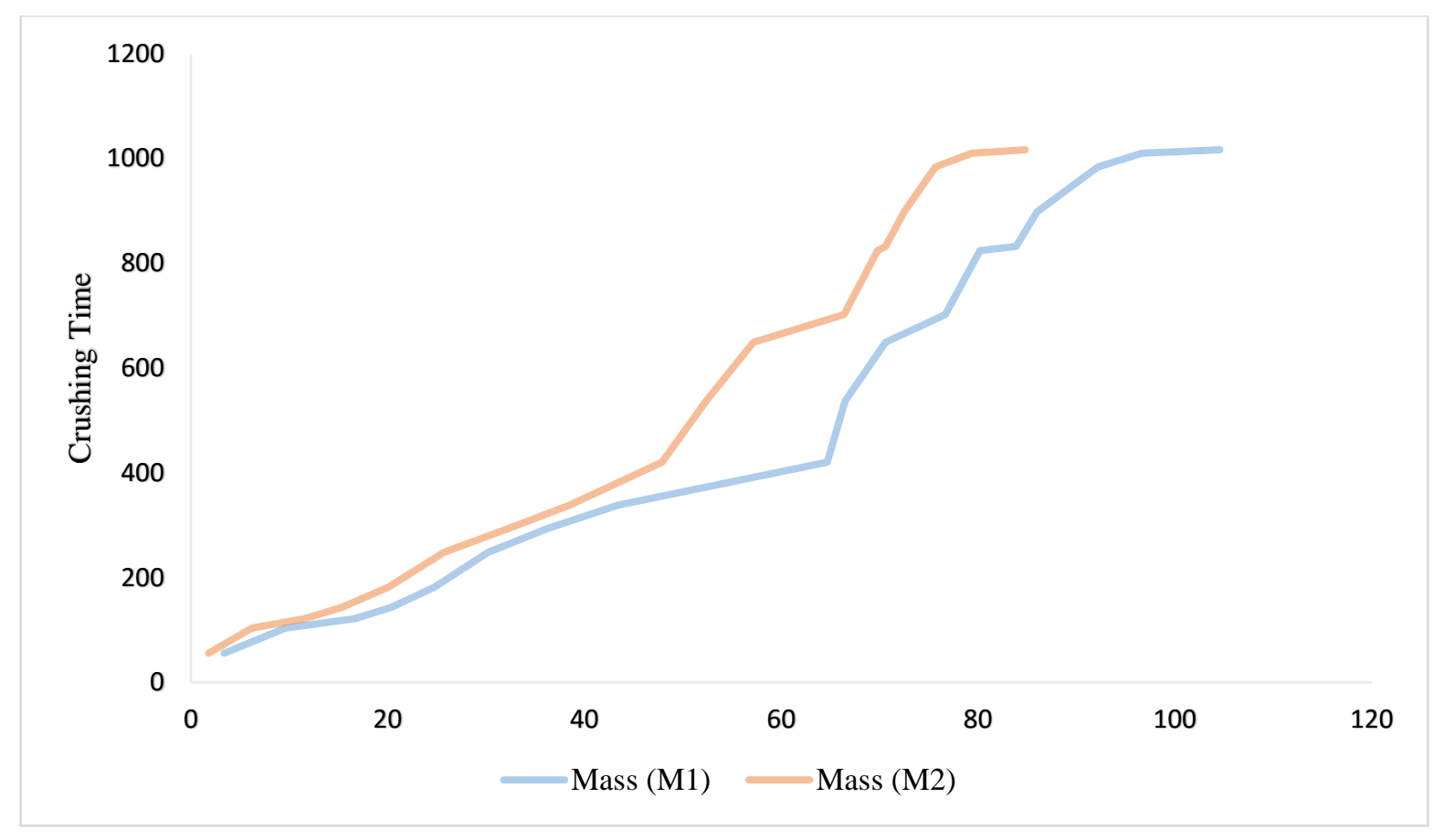

Fig. 8. Mass of properly crushed PET plastic waste bottle against crushing time.

The crushing time is a function of properly crushed PET bottles. As shown in Fig. 8, as the mass of properly crushed plastic waste increases, the crushing time increase as well. This implies that there is a linear relationship between crushing time and masses of crushed PET bottles.

\subsection{Computer Aided Design Analysis}

The following analysis was carried out on the cutting blade using SOLIDWORKS to design and simulate the stresses and also to examine the variations of stress distribution at different force applications. The factor of safety was maintained at 8 . Static analysis was carried out by applying varying forces of $1000 \mathrm{~N}-3000 \mathrm{~N}$ to the cutting blade, and the stress variations resulting from the forces were recorded. Table 4 shows properties of the material used for the crushing blade design. 
Table 4. Material Properties of the crushing blade

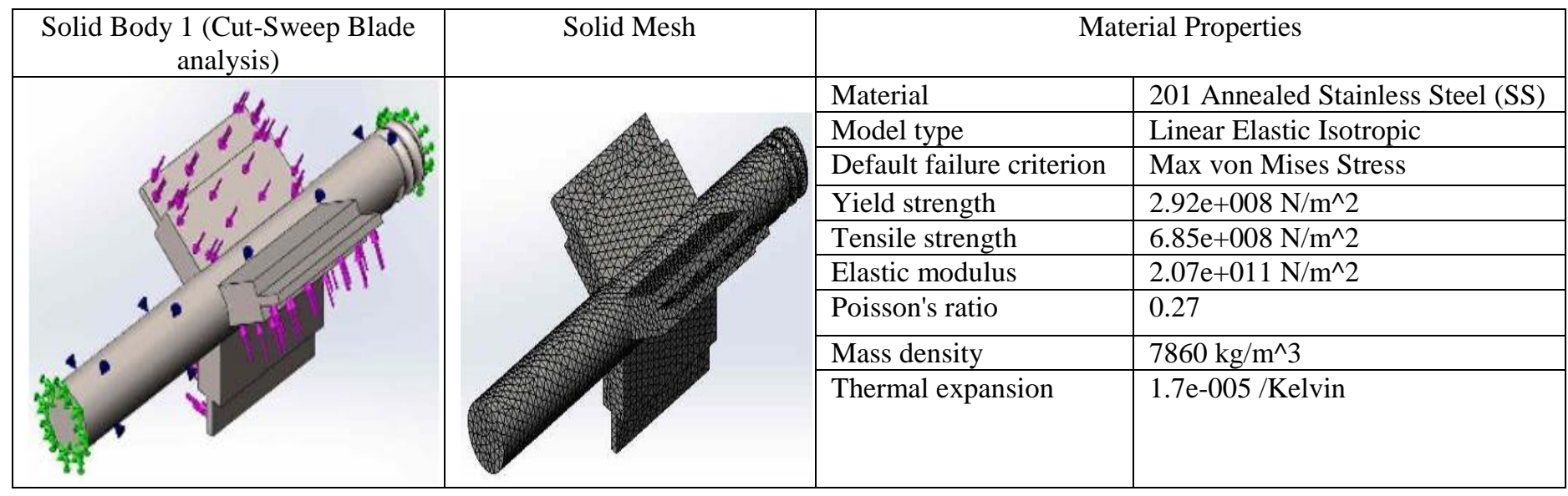

This indicates the forces acting on the machine shaft due to the bearing connector. A bearing connector allows rotation in only one axis. During operation forces are set up which the bearings must withstand from the shaft. Table 5 represents the axial, shear and reaction force components in the $\mathrm{X}, \mathrm{Y}$, and $\mathrm{Z}$ directions respectively.

Table 5. Bearing Connector Forces

\begin{tabular}{|l|c|c|c|c|}
\hline Type & X-Component & Y-Component & Z-Component & Resultant \\
\hline Axial Force $(\mathrm{N})$ & 0 & 0 & $-3.5353 \mathrm{e}-011$ & $3.5353 \mathrm{e}-011$ \\
\hline Shear Force $(\mathrm{N})$ & $1.9749 \mathrm{e}-009$ & $-3.7355 \mathrm{e}-008$ & 0 & $3.7407 \mathrm{e}-008$ \\
\hline Reaction Force $(\mathrm{N})$ & $6.79065 \mathrm{e}-005$ & $-2.55265 \mathrm{e}-005$ & $2.51748 \mathrm{e}-007$ & $7.25462 \mathrm{e}-005$ \\
\hline
\end{tabular}

\subsection{Design Study}

The following are results obtained when the blade was subjected to forces ranging from $1000 \mathrm{~N}$ to $3000 \mathrm{~N}$ using
Annealed stainless steel as material, and the maximum Vonmises stresses induced are tabulated in Table 6. Fig. 9 represents a graph of maximum Von-Mises stresses against applied force.

Table 6. Von Mises Stress Induced as a Result of Varying Force

\begin{tabular}{|c|c|c|c|c|c|c|}
\hline Parameters & Units & Scenario 1 & Scenario 2 & Scenario 3 & Scenario 4 & Scenario 5 \\
\hline Force & $\mathrm{N}$ & 1000 & 1500 & 2000 & 2500 & 3000 \\
\hline Material & $\mathrm{N} / \mathrm{A}$ & $\begin{array}{c}201 \text { Annealed } \\
\text { Stainless Steel } \\
(\mathrm{SS})\end{array}$ & $\begin{array}{c}\text { 201 Annealed } \\
\text { Stainless Steel } \\
(\mathrm{SS})\end{array}$ & $\begin{array}{c}\text { 201 Annealed } \\
\text { Stainless Steel } \\
(\mathrm{SS})\end{array}$ & $\begin{array}{c}\text { 201 Annealed } \\
\text { Stainless Steel } \\
(\mathrm{SS})\end{array}$ & $\begin{array}{c}\text { 201 Annealed } \\
\text { Stainless Steel } \\
(\mathrm{SS})\end{array}$ \\
\hline Constraints & $\left(\mathrm{N} / \mathrm{m}^{2}\right)^{\wedge} 2 / \mathrm{Hz}$ & 0.000000 & 0.000000 & 0.000000 & 0.000000 & 0.000000 \\
\hline $\begin{array}{c}\text { Max Von } \\
\text { Mises Stress }\end{array}$ & $\mathrm{N} / \mathrm{m}^{2}$ & $6.9646 \mathrm{e}+005$ & $1.0447 \mathrm{e}+006$ & $1.3929 \mathrm{e}+006$ & $1.7412 \mathrm{e}+006$ & $2.0894 \mathrm{e}+006$ \\
\hline
\end{tabular}




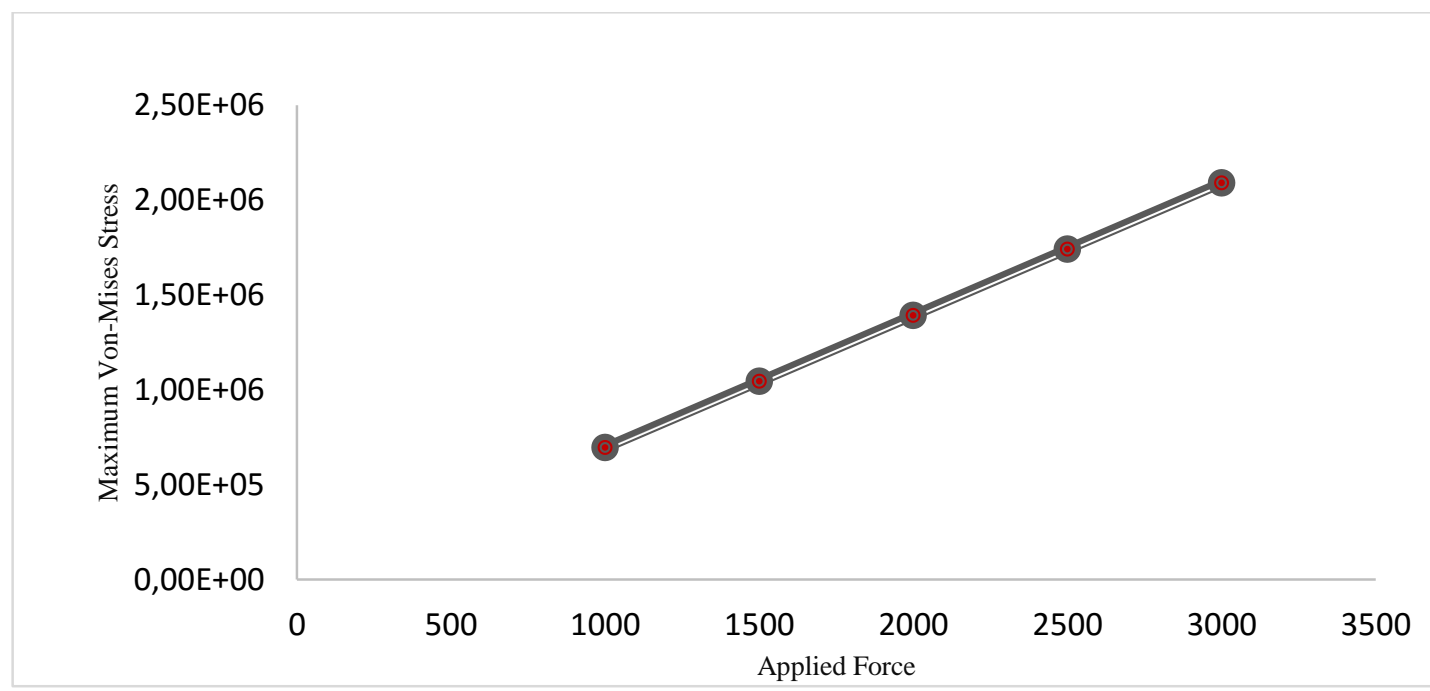

Fig. 9. Graph of Maximum Von Mises Stresses against Applied Force.

\subsection{Static Stress Analysis}

stresses and displacement were obtained as shown in Fig 10

Using maximum force of $3000 \mathrm{~N}$ to analyze the PET and 11 respectively. bottles crushing blade design model, the following Von-mises

Model name:Bl ade for analysis

Study nameistatic 1 - $D$ ef ault-I
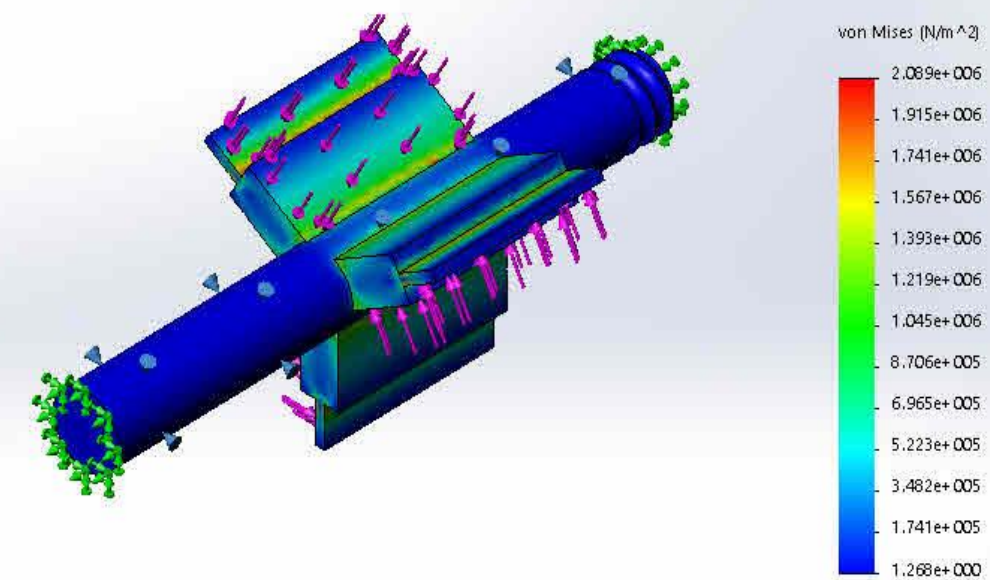

1.

$\rightarrow$ Kield strength: $2.920 \mathrm{e}+008$

Fig. 10. Result of Von-mises Stress Obtained from the Crushing Blade Analysis. 

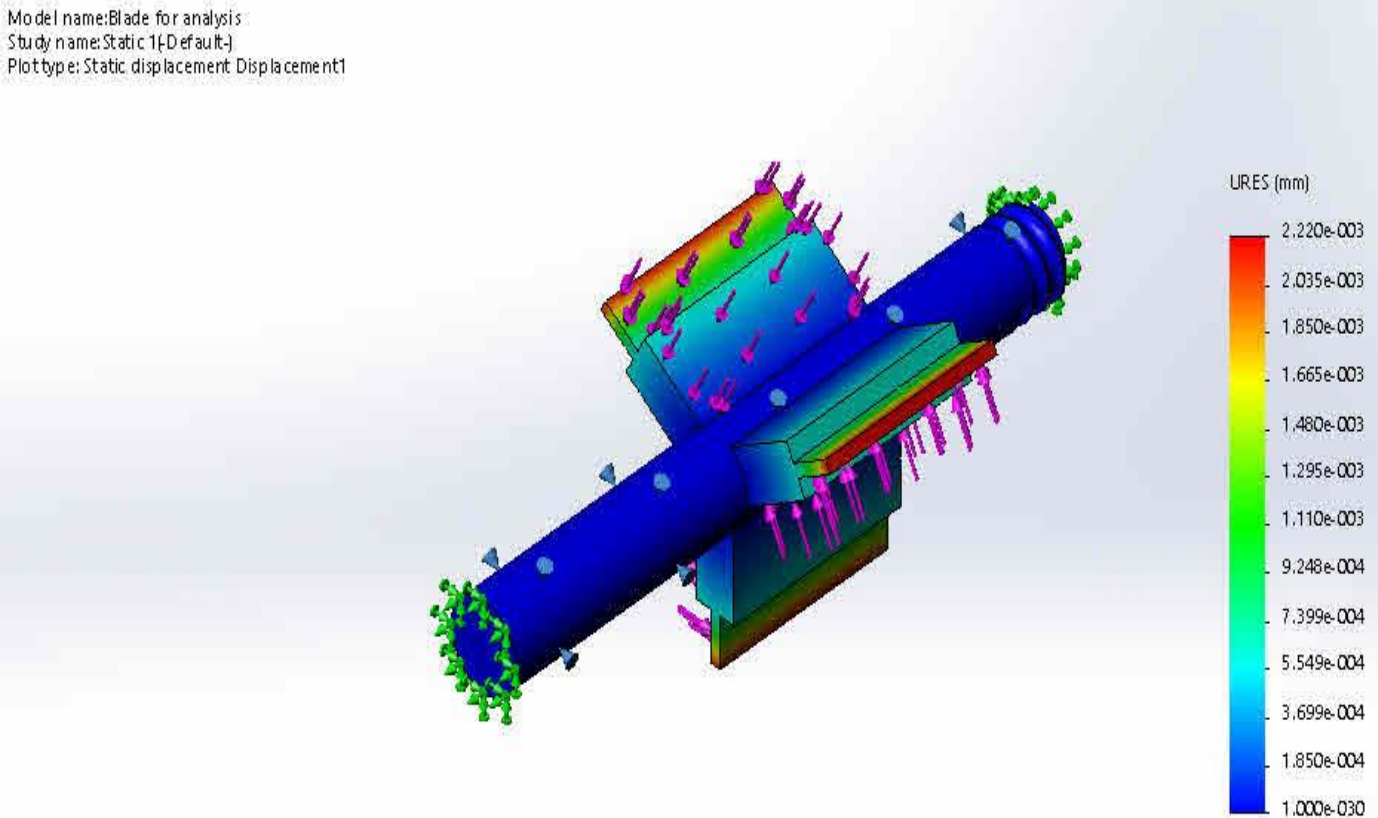

Fig. 11. Result of Displacement Obtained from the Crushing Blade Analysis.

It can be seen from the above that when a force of $3000 \mathrm{~N}$ is applied on the cutting blade with all the conditions stated above taken into consideration, The maximum von Mises stress is $2.089 \mathrm{e}+006 \mathrm{~N} / \mathrm{m}^{\wedge} 2$ at Node: 8523 , and the minimum is $1.268 \mathrm{e}+000 \mathrm{~N} / \mathrm{m}^{\wedge} 2$ at Node: 10247 . The yield stress of the material was found to be $2.92 \mathrm{e}+008 \mathrm{~N} / \mathrm{m}^{\wedge} 2$, and applying a force of $3000 \mathrm{~N}$ on the cutting blade produced a maximum displacement of $2.220 \mathrm{e}-003 \mathrm{~mm}$. This therefore implies that the material will not fail when subjected to a force or load equal to and below that value. The machine temperature during operation was $3 \mathrm{~K}$ which is in the safe zone and will not result in any temperature deformation of the bottles.

\section{Conclusion}

PET bottles crushing machine was successfully designed in this study. The plastic bottle crushing machine was designed for PET bottles as well as plastic waste recycling mainly for commercial and industrial applications. Performance evaluation was carried out on the crushing machine and the results obtained indicated that the machine was efficient and could be used for reduction of PET bottle wastes littering our environment particularly in developing countries where there is insufficient technologies to handle this menace. The designed PET bottles crushing machine can be used to reduce the volume of PET bottle wastes dump indiscriminately, and this will ensure the wellbeing of the world's populace in a healthy environmental condition. Moreover, efficiency of $82.2 \%$ was recorded for the machine design which indicated that the machine can be used industrially in a small scale.

\section{References}

[1] C. O. Aguoru and C. A. Alu, Studies on Solid Waste Disposal and Management Methods in Makurdy and its Environs North North Central Nigeria. Greener Journal of Environmental Management and Public Safety, Vol. 4, No. 2, pp. 019-027, 2015.

[2] S. Ojoawo, O. Agbede and A. Sangodoyin, On the Physical Composition of Solid Wastes in Selected Dumpsites of Ogbomosoland, South Western Nigeria. Journal of Water Resource and Protection, Vol. 3, No. 9, 2011.

[3] I. Igbinomwanhia, Status of Waste Management, Integrated Waste Management-Volume II, 11-34, ISBN: 978-953-307-447-4. Intech Europe, University Campus STeP Ri, Slavka Krautzeka 83/A. 51000 Rijeka, Croatia, 2011.

[4] T. Al Seadi, Good practice in quality management of AD residues from biogas production. Report made for the International Energy Agency, Task 24- Energy from Biological Conversion of Organic Waste. IEA Bioenergy and AEA Technology Environment, Oxfordshire, United Kingdom, 2001.

[5] A. Tukur, PET bottle use patterns and antimony migration into bottled water and soft drinks: the case of British and Nigerian bottles. Journal of Environmental Monitoring, Vol. 14, No. 4, pp. 1236-1246, 2012.

[6] J. Hopewell, R. Dvorak, and E. Kosior, Plastics recycling: challenges and opportunities. Philosophical Transactions 
of the Royal Society B: Biological Sciences, Vol. 364, No. 1526, pp. 2115-2126, 2009.

[7] B. Allen, Demand for PET Packaging Material to reach $\$ 60$ billion by 2019 , Smithers Pira. [online] available at http://www.smitherspira.com/news/2014/april/demandfor-pet-packaging-material-in-2019, 2017.

[8] K. W. Hayden, A. Jaimys, J. C. Russell, and P. I. Elena, Plastic Degradation and Its Environmental Implications with Special Reference to Poly (ethylene terephthalate) Polymers, Vol. 5, No 1, pp. 1-18, 2013.

[9] E. Metin, A. Erozturk and C. Neyim, solid waste management practices and review of recovery and recycling operations in turkey. Waste management, Vol. 23, No. 5, pp. 425-432, 2003.

[10] B. Oseni, Municipal Solid Waste Management in Developing Countries (Part II), Environment of Nigeria. [online] available at http://nigeriaenvironment.blogspot.com.ng/2012/12/muni cipal-solid-waste-management-in_11.html?m=1, 2012.
[11] J. F. Tester, E. M. Drake, J. M. Driscoll, W. M. Golay, and A. W. Peters, Sustainable Energy-Choosing Among Option. PHI Learning Private Limited, New Delhi110001, ISBN: 9788120329034, 2005.

[12] A. Bruvoll, Factors influencing solid waste generation and management. Journal of solid waste technology and management, Vol. 27, No. 3/4, pp. 156-162, 2001.

[13] European Commission, End-of-Waste Criteria for Waste Plastic for Conversion-Technical Proposals, Final Draft Report March 2013, IPTS Seville, Spain. Institute for Prospective Technological Studies, 2013.

[14] C. A. Harper, E. M. Petrie, and E. Corporation, Plastics materials and processes, Wiley Online Library, 2003.

[15] C. C. Ugoamadi and O. K. Ihesiulor, Optimization of the Development of a Plastic Recycling Machine. Nigerian Journal of Technology, Vol. 30, No 3, pp. 67-81, 2011. 